\title{
ЧЕЛОВЕЧЕСКИЙ КАПИТАЛ КАК СОСТАВЛЯЮЩАЯ ФИНАНСОВОГО ПОТЕНЦИАЛА ДОМАШНИХ ХОЗЯЙСТВ
}

\author{
А. Б. Унтанов \\ Байкальский государственный университет, г. Иркутск, Российская Федерация
}

\author{
Информация о статье \\ Дата поступления \\ 6 июня 2017 г. \\ Дата принятия к печати \\ 20 ноября 2017 г. \\ Дата онлайн-размещения \\ 27 ноября 2017 г. \\ Ключевые слова \\ Человеческий капитал; оценка \\ человеческого капитала; \\ фринансы домашних хозяйств; \\ фринансовый потенциал; \\ финансовый учет
}

\begin{abstract}
Аннотация
В работе рассматривается роль человеческого капитала в составе финансов домашних хозяйств, отражается проблема идентификации финансового потенциала домашних хозяйств как самостоятельного явления, анализируются существующие исследования по указанной проблеме. На основании данного анализа представлена авторская позиция в определении состава и структуры финансового потенциала домашних хозяйств, в частности отмечается, что он включает в себя как стоимостную оценку их ресурсов, так и способность хозяйствующих субъектов формировать финансовый результат. Использование метода сравнительного анализа в рамках экономического подхода сделало возможным обосновать значительное сходство домашних хозяйств и коммерческих предприятий. Данный метод способствовал формированию модели финансового учета домохозяйств, наиболее полному отражению состава и структуры фринансового потенциала, что позволило изучить место человеческого капитала в нем.
\end{abstract}

\section{HUMAN CAPITAL AS A COMPONENT OF HOUSEHOLD FINANCIAL CAPACITY}

\author{
Aleksander B. Untanov \\ Baikal State University, Irkutsk, Russian Federation
}

\section{Article info}

Received

June 6, 2017

Accepted

November 20, 2017

Available online

November 27, 2017

\section{Keywords}

Human capital; human capital assessment; household finance; financial capacity; financial accounting

\begin{abstract}
The research paper considers a role of human capital as a component of household financial capacity as well as an issue of identifying financial capacity of households as a separate phenomenon. An analysis of current studies on the above issue is carried out and is used to back up the author's point of view on determining components and structure of household financial capacity. In particular, it is noted that household financial capacity includes both valuation of household resources and ability of economic entities to achieve financial results. The assumption that households bear similarity to business enterprises is justified by means of comparative analysis carried out within the economic approach. The application of the given method allows the author to build a model of household financial accounting and fully reflect components and structure of financial capacity, which in its turn allows for studying the role human capital plays in the latter.
\end{abstract}

Феномен человеческого капитала был и остается неоднозначным явлением, которым интересуются многие исследователи. К настоящему времени отношение к нему существенно изменилось. Так, в частности, большинство научных трудов последних лет подтверждает значительное влияние человеческого капитала на многие экономические и фринансовые показатели. Кроме того, интерес ученых обусловливается и тем, что человеческий капитал рассматривается в различных отраслях науч- ного знания. Так, В. И. Самаруха исследует влияние человеческого капитала на экономическое развитие региона и страны и поднимает проблему финансирования человеческого капитала на местном уровне [1]. С. А. Курганский изучает теоретическое обоснование человеческого капитала, а также затрагивает проблему его идентификации с позиции различных институтов [2]. При этом актуальным остается также вопрос влияния человеческого капитала на финансы домашних хозяйств. 
Важно понимать, что человек является основой домашнего хозяйства, его неотъемлемой частью. В свою очередь, человеческий капитал, который может быть представлен в виде знаний, опыта и навыков, не может быть отчужден другому лицу, поэтому он неотделим от своего носителя и становится собственностью домашних хозяйств.

Как следствие, любые решения, принимаемые в домашних хозяйствах, тесно связаны с человеческим капиталом, т. е. они влияют на общие результаты деятельности хозяйствующих субъектов и на их финансовый потенциал.

Понимание места и роли человеческого капитала в системе финансовых отношений домашних хозяйств позволит значительно продвинуться в исследованиях фринансового потенциала.

На сегодняшний день человеческий капитал - крайне неоднозначное явление, которое, вне сомнений, играет значительную роль в развитии как экономики государства, так и социальной, политической сфер жизни общества. Широкое определение человеческого капитала как сложного производительного фактора делает это понятие системным и комплексным, что соответствует его реальной сущности и ведущей роли в процессах формирования и развития инновационной экономики и информационно-инновационного общества.

Очевидно, что страны, имеющие значительные запасы человеческого капитала, обладают огромным преимуществом в создании условий для роста социальной и экономической сфер жизни. Это неудивительно, поскольку здоровое, образованное население, имеющее высокопрофессиональные навыки, - это залог и основа стабильного экономического роста страны.

Примечательна и история исследования человеческого капитала и отношения общества к этому явлению. До 1950-х гг., когда еще не существовало самого термина «человеческий капитал», рабочая сила рассматривалась учеными как нечто данное и неизменное. Кардинальные изменения в этом направлении произошли после выхода пионерских работ Т. У. Щульца, Г. С. Беккера [3; 4] в начале второй половины XXв. Определив приобретаемые людьми навыки и знания в качестве особой формы капитала, они обратили внимание на последствия, которые имеют инвестиции, направляемые на развитие человека, для экономического роста.

Несомненно, что изначально указанные работы подверглись существенной критике, поскольку сама мысль сравнения людей с машинами была оскорбительной. Отношение к образованию как к инвестициям, а не как к приобщению к культурному опыту считалось бессердечным. Однако впоследствии на данную теорию стали смотреть более лояльно, и интерес к человеческому капиталу начал возрастать. В результате понятие человеческого капитала стало общеупотребительным, его активно использовали при обсуждении самых разных экономических и социальных проблем современных обществ. Обозначенные и более поздние работы послужили основой для развития теории человеческого капитала, которая и по сей день является предметом исследования многих ученых. Стоит отметить, что в своих исследованиях они также оперируют понятием «человеческий потенциал». При этом не всегда четко определяется грань между данными явлениями. Безусловно, эти понятия тесно связаны между собой, однако человеческий потенциал не имеет на сегодняшний день однозначного общепринятого толкования. В связи с этим его часто путают с такими понятиями, как «человеческий капитал», «трудовой потенциал» и «кадровый потенциал». При этом, если трудовой и кадровый потенциалы могут быть приравнены к человеческому потенциалу только в частных случаях, то отождествление с человеческим капиталом достаточно распространено.

Некоторые авторы все же различают эти понятия и отмечают, что мотивы, нравственность и культура человека являются отличительными чертами человеческого потенциала [5, с. 17]. Более того, в отличие от теории человеческого капитала, постулирующей исключительно экономическую роль человека, концепция человеческого потенциала учитывает в первую очередь ценность самой жизни человека и среды его существования. Как результат, в настоящее время отсутствуют способы количественной оценки человеческого потенциала в его широком смысле. Изучение человеческого капитала как частной формы проявления человеческого потенциала в этом плане продвинулось несколько дальше, в результате чего человеческий капитал и его влияние на экономическую жизнь общества представляют практический интерес для исследователей.

Несмотря на то что человеческий капитал является частью экономики страны и оказывает значительное влияние на экономические процессы и их участников, носителем человеческого капитала выступает человек, и по своей природе не может быть отчужден другому субъекту, т. е. человек был и оста- 
ется единственным собственником человеческого капитала. Данный фракт обусловливает большое количество особенностей при идентификации рассматриваемого явления.

Участие в развитии человеческого капитала принимают все субъекты экономики. Например, для его сохранения и развития крайне важны образование и здравоохранение, однако в большинстве случаев без поддержки государства человеку сложно организовать самостоятельную подготовку. Другим ярким примером являются специализированные навыки и умения, нужные в определенной области. Работодатель предоставляет необходимую информацию и создает условия для практики с целью развития данных аспектов человеческого капитала.

Получается, что третьи по отношению к человеку лица воздействуют на человеческий капитал косвенно, при помощи формирования социальных институтов. Такого рода ассигнования, тем не менее, не позволяют инвесторам в полной мере распоряжаться объектом инвестиций, а лишь дают возможность пользоваться результатами реализации человеческого капитала.

Несмотря на то что в теории домашних хозяйств имеется множество суждений касательно идентификации домохозяйства как самостоятельного явления [6; 7], можно выделить основные признаки, присущие всем домашним хозяйствам:

- наличие одного и более людей, проживающих на совместной территории;

- организация совместной деятельности по ведению хозяйства; сами;

- распоряжение определенными ресур-

- самостоятельное принятие хозяйственных решений;

- стремление к обеспечению принципа эфрфективности.

Важно отметить, что именно человек составляет основу домашнего хозяйства, а значит, человеческий капитал, будучи неотделимым от человека, представляет собой собственность домашнего хозяйства. Как следствие, любое решение, принятое его членами, будет в значительной мере зависеть от имеющегося человеческого капитала. Организационная структура и результаты хозяйственной деятельности также не являются исключением. Поэтому крайне важно определить роль и место человеческого капитала в рамках фринансового потенциала домашних хозяйств.

Интересен тот фракт, что некоторые авторы осуществляют оценку человеческого капитала на предприятии, прослеживая взаимосвязи с производственной деятельностью, рыночной стоимостью и имуществом [8], и, хотя оценка выполняется не в количественной форме, результаты исследований указывают на высокую корреляционную зависимость финансового результата от навыков человека. Вне сомнений, что работник является одним из основных факторов производства на предприятии, поэтому его личные качества и характеристики в виде навыков и опыта будут влиять на результаты хозяйственной деятельности. В результате логично предположить, что для финнансового потенциала домашних хозяйств человеческий капитал играет не меньшую роль. Однако финансовый потенциал домашних хозяйств представляется еще одной дилеммой в изучении данного вопроса по причине отсутствия в должном объеме исследовательского опыта как в отечественной, так и в зарубежной практике.

Затруднения возникают уже на начальном этапе при идентификации финнансового потенциала домашних хозяйств. Существующие работы в этом направлении определяют его как совокупность располагаемых домашним хозяйством финансовых ресурсов и финансового богатства, которые могут быть использованы для реализации разнообразных потребностей домохозяйства и решения задач развития каждого из его участников [9; 10]. При этом состав финансовых ресурсов и финансового богатства у авторов различается. Так, неопределенными остаются место имущества в движимой и недвижимой форме и роль заемных средств. Имеющиеся противоречия создают путаницу, которая затрудняет дальнейшие исследования.

Опыт государственных и корпоративных финансов по данному вопросу, однако, позволяет определить основные признаки фринансового потенциала. Проанализировав имеющиеся точки зрения, можно сделать вывод, что исследователи финансового потенциала в государственном и корпоративном секторах связывают его либо со стоимостной оценкой величины финансового потенциала [11; 12], либо со способностью хозяйствующего субъекта формировать финансовый результат $[13 ; 14]$.

Определение термина «потенциал», с одной стороны, обусловливает наличие ресурсов и имущества как условий для существования фринансового потенциала, а с другой стороны, отмечает необходимость их непосредственного использования для достижения поставленных целей. Ресурсы как таковые, находящиеся в распоряжении субъ- 
екта, не являются финансовым потенциалом, необходим процесс их вовлечения в деятельность субъекта с возможностью получения потенциального результата. Следовательно, финансовый потенциал - это способность субъекта формировать финансовый результат, используя доступные ресурсы.

Однако, рассматривая фринансовые ресурсы как стоимостное выражение финансового потенциала хозяйствующего субъекта, важно понимать, что не только они в их классическом понимании включаются в расчет. Также будет учитываться стоимостная оценка материальных запасов, дебиторской задолженности и внеоборотных активов [12, с. 82]. Таким образом, все имущество, участвующее в хозяйственной деятельности субъекта, является ресурсной составляющей финансового потенциала. В результате основным критерием выступает возможность денежного выражения стоимости ресурсов, а также участие этого имущества в хозяйственной деятельности субъекта. Принимая во внимание тот факт, что финансовые ресурсы в виде денежных средств и эквивалентов являются не единственным фактором, формирующим результат хозяйственной деятельности, можно считать данное предположение верным.

Для полноты и наглядности отражения состава и структуры финансового потенциала домашних хозяйств, места человеческого капитала в них будет интересным и полезным сравнить домашние хозяйства с коммерческими организациями.

Примечательно, что рассмотрение домашних хозяйств в качестве коммерческих организаций в работах отечественных исследователей в настоящее время не снискало значительного интереса. Однако экономическое сходство в принятии решений, направленных на максимизацию получаемого результата, было подмечено еще Г. С. Беккером в рамках экономического подхода.

Зарубежные работы, в которых домашние хозяйства представлены как коммерческие фирмы [15; 16], позволяют построить своеобразную информационную модель, иллюстрирующую результаты их фринансовой деятельности, выявляющую основные компоненты имущества и источников имущества домашних хозяйств. Такой информационной моделью может стать финансовая отчетность домохозяйств (баланс, отчет о доходах и расходах, а также отчет о движении денежных средств). Так, уже существующие исследования [16] определяют человеческий капитал как часть нематериальных активов домашнего хозяйства.
Баланс домашних хозяйств включает активы и пассивы. Первые состоят из реальных активов, к которым относятся физические (движимое и недвижимое имущество, материальные запасы) и фринансовые (денежные средства, фринансовые вложения) активы, а также неосязаемые активы в виде человеческого капитала. Пассивы включают богатство (первоначальный капитал, безвозмездные поступления, сбережения) и обязательства (задолженность по кредитам и прочие займы).

Существуют, однако, определенные противоречия в квалификации человеческого капитала в данном случае, поскольку человеческий капитал одновременно имеет сходные основания как с материальными, так и с нематериальными активами. Так, знания, опыт, навыки не обладают физической формой, и хотя они заключены в человеческий мозг, последний должен осуществлять работу в виде мыслительных процессов, но работа человеческого мозга невещественна и поэтому относится к нематериальному капиталу. При этом фризическое тело человека как материальный актив включает состояние здоровья, на поддержание которого требуются расходы, и имеет ограниченный срок «службы»"

С одной стороны, отнесение человеческого капитала к нематериальным активам нельзя полностью считать корректным, поскольку материальная составляющая имеет быть, с другой стороны, человеческий капитал в первую очередь ассоциируется со знаниями, опытом и навыками, а физическое тело человека значительно отличается от материальных активов главным образом спецификой формирования стоимости и начисления амортизации.

Проблему в этом случае представляет собой и оценка человеческого капитала. Специфическая природа рассматриваемого явления обусловливает многообразие методов оценки, а также их сложность. Существующие на сегодняшний день методы поражают своим многообразием. В целом их можно условно разделить на четыре группы:

1 Можно также предположить, что человеческий капитал является источником имущества наравне с собственным или заемным капиталом, а реальные проявления человеческого капитала (знания, опыт и т. д.) должны непосредственно связываться с имуществом. Однако такой подход не совсем жизнеспособен, неясно, какими компонентами будет представлен человеческий капитал в качестве пассива. Более того, источником формирования знаний, опыта, навыков вполне могут быть как заемные источники, так и собственные. В таком контексте совершено неясно место человеческого капитала ни в качестве самостоятельного элемента пассивов, ни как часть собственного капитала. 
1. Индикаторный метод оценки.

2. Оценка по остаточному принципу.

3. Оценка на основе издержек, связанных с формированием человеческого капитала.

4. Оценка на основе потенциальных доходов от реализации человеческого капитала.

Индикаторный анализ основывается на расчете корреляции между факторами, оказывающими влияние на человеческий капитал: образование, возраст, пол, расовая принадлежность и т. д. При этом данный подход не подразумевает денежное выражение величины человеческого капитала, что можно назвать важным преимуществом, поскольку «натуральные» измерители при всей их очевидной условности значительно расширяют возможности анализа.

По этой причине данный способ расчета популярен и в настоящее время. Большое количество зарубежных авторов выбирают именно индикаторный анализ, так как информация об уровне и качестве образования доступна. Так, некоторые авторы производят оценку школьного образования во многих странах на основе измерения уровня грамотности населения, определения среднего количества лет обучения [17]. Другие обосновывают интенсивное влияние человеческого капитала на экономический рост за счет более лояльного отношения населения к технологическим нововведениям [18]. Также поднимается вопрос о различиях между агрегированной величиной человеческого капитала и индивидуальным человеческим капиталом. Авторы исходят из того, что суммарная величина индивидуального человеческого капитала может не равняться агрегированному значению, поскольку природа данных явлений несколько разнится [там же].

В большинстве исследований уделяется внимание лишь одному из источников формирования человеческого капитала - образованию. Считаем, что это ограничение не может являться критическим по причине ключевой роли образования для характеристики в современных обществах механизма «производства» знаний, навыков и компетенций.

Оценка по остаточному принципу используется Всемирным банком². Для данного метода вначале рассчитывается совокупное благосостояние страны как дисконтированная величина потоков будущего потребления. Из этой величины вычитается физический и природный капитал, полученный остаток в данном случае равен нематериальному капиталу, который в масштабе страны состоит

2 World Bank. Where is the Wealth of Nations? Washington : World Bank, 2006. 188 p. из человеческого капитала, социального капитала и т. д. Способ достаточно прост и унифицирован для расчетов по всем странам, однако имеет множество недостатков. Во-первых, сложно выявить точную величину человеческого капитала, а во-вторых, метод не учитывает того, что инвестиции могут быть совершены за счет формирования долговых обязательств.

Метод, ориентированный на оценку издержек, связанных с производством человеческого капитала, изначально был ориентирован на измерение кумулятивных затрат, направленных на его фрормирование за вычетом амортизации. Впоследствии в работах Ф. Махлупа акцент исследований сместился с измерения издержек по содержанию людей на измерение затрат, связанных с улучшением их качественных характеристик, что и являлось инвестициями в человеческий капитал [19]. Именно тогда впервые упоминается понятие альтернативных издержек времени, которое затрачивают учащиеся на фрормирование своего человеческого капитала.

Объединение имеющихся подходов произошло в работах Дж. Кендрика [20]. Все активы, воплощенные в человеке, делились им на две части - осязаемые и неосязаемые. Первые - это аккумулированные издержки по содержанию детей до трудоспособного возраста, вторые - издержки, связанные с повышением качества труда.

Метод был проработан и считался прогрессивным, однако обладал явными ограничениями и недостатками. Отсутствовал четкий принцип разделения инвестиционных и потребительских расходов, при этом открытым остался вопрос о способе начисления амортизации, поскольку человеческий капитал определенно отличается от физического. Однако основная проблема кроется в самой сути данного метода, так как величина человеческого капитала измеряется исключительно на стороне производства. Это означает, что ценность определяется полностью на стороне предложения, не затрагивая фактор спроса.

Развитие метода, основанного на учете доходов населения, связано с именами У. Петти и У. Фарра. Так, согласно видению У. Фарра, оценка человеческого капитала осуществляется на основе определения капитализированной стоимости будущих доходов индивидов за вычетом их расходов на содержание самих себя с учетом корректировки на вероятность смертности [21, с. 4]. Именно в работах У. Фарра была сорормулирована ключевая идея, что капитал, воплощенный в индивидах, можно оценивать исходя из сум- 
марного дохода, который им предстоит получить на рынке в течение последующей жизни.

Весомый вклад в развитие данного метода оценки человеческого капитала привнесли работы Д. Джоргенсона и Б. Фраумени. Им удалось значительно упростить процедуру расчета приведенной величины пожизненных заработков. Более того, авторы исследовали так называемые нерыночные составляющие человеческого капитала, приводя способы оценки нерыночных услуг, которые фрормирует человеческий капитал [22, с. 20].

Несомненно, недостатков у данного метода также много, некоторые критики скептически относятся к расчету «нерыночных» видов деятельности. Кроме того, этот метод является достаточно затратным. Расчет включает только потребление, следовательно, стоимость формируется на стороне спроса, хотя расчеты У. Фарра учитывают расходы на содержание человеком самого себя. В дальнейшем исследователи отказались от этой идеи.

В конечном итоге для целей текущего исследования наибольший интерес представляет затратный метод, основанный на формировании издержек производства. Он позволяет оценить балансовую стоимость человеческого капитала, в результате чего оценка финансового потенциала домашних хозяйств сможет учитывать эту переменную. Аналогичная ситуация с доходным методом, отражающим способность человеческого капитала приносить доходы своему владельцу и формировать финансовый результат. Стоимость же выражается дисконтированной величиной будущих доходов от реализации человеческого капитала ${ }^{3}$.

Возникает единственный вопрос, который определяет роль человеческого капитала в структуре финансового потенциала домохозяйств: если человеческий капитал и его балансовая стоимость являются частью имущества домашних хозяйств, включается ли она в состав ресурсов, используемых для формирования фринансового результата

\footnotetext{
${ }^{3}$ При этом наличие отдельно затратного и доходного методов оценки человеческого капитала наталкивает на интересную мысль. Представив человеческий капитал в роли инвестиционного капитала, можно объединить два рассмотренных выше метода в один, инвестиционный метод. Таким образом, затраты, совершенные для формирования человеческого капитала, - это инвестиции, а доходы, которые приносит человеческий капитал, - это денежные потоки, формирующиеся от реализации инвестиционного проекта. Такой подход может быть интересен как самим домашним хозяйствам, так и государству в лице общества. Он позволяет оценить экономическую эффективность инвестиций в человеческий капитал.
}

деятельности хозяйствующих субъектов? Ответить на него сразу достаточно сложно, поскольку одни авторы связывают финансовый потенциал с финансовыми ресурсами и богатством, другие оперируют только финансовыми ресурсами. Последнее означает, что фринансовый потенциал связан исключительно с денежными средствами. Большинство исследователей склонны относить сюда все имущество хозяйствующего субъекта, а человеческий капитал, согласно ранее сделанным выводам, является таковым. Однако специфика человеческого капитала как имущества не позволяет с полной уверенностью ставить его в ряд с остальными активами. Неотделимость от носителя и, как следствие, невозможность обращения в полной мере на открытом рынке, неоднозначность в формировании стоимости и начислении амортизации - все это заставляет усомниться в необходимости определения места человеческого капитала в структуре финансового потенциала.

При этом доходы, генерируемые домашним хозяйством в результате деятельности, могут внести ясность в имеющуюся проблему. Современные исследователи привыкли считать заработную плату членов домохозяйств частью финансового потенциала, совершенно не задумываясь об источнике ее формирования. Так, согласно еще классическим взглядам К. Маркса, заработная плата является оплатой рабочему его способности к труду. Работодатель покупает не сам труд, а способность человека к нему, говоря другими словами, он арендует у работника набор навыков, способностей, умений и т. д. Следовательно, заработная плата является результатом реализации человеческого капитала для домашнего хозяйства.

В итоге финансовый результат в своем привычном понимании включает в себя доходы, созданные за счет реализации человеческого капитала. Складывается ситуация, когда некоторые расчеты значительно завышаются, поскольку совокупные результаты хозяйственной деятельности сопоставляются с активами, пассивами, частью определенного имущества или капитала и не учитывают влияние человеческого капитала. Если на предприятии данный шаг оправдан его сильной размытостью и неопределенностью, то в рамках домашних хозяйств такое решение крайне неоправданно.

Так, заработная плата составляет подавляющую долю в совокупных рыночных доходах домашних хозяйств. Зачастую люди осуществляют предпринимательскую 
деятельность на базе своего домашнего хозяйства. Более того, стоит также выделить «нерыночные» виды деятельности, когда товары и услуги, производимые домашним хозяйством, не реализуются на открытом рынке, а потребляются внутри домашнего хозяйства. Во всех этих случаях можно говорить о реализации человеческого капитала.

Существующая специфика человеческого капитала для некоторых может показаться критичной, сам фракт необходимости его оценки в структуре финансового потенциала домашних хозяйств остается неизменным. В случае исключения человеческого капитала из состава имущества, участвующего в создании фринансового потенциала, требуется кардинальный пересмотр компонентов финансового результата. Заработная плата членов домохозяйств должна быть исключена из совокупных доходов, а доходы от предпринимательской деятельности необходимо уменьшить на долю, сорормированную за счет человеческого капитала. Это, в свою очередь, порождает новые вызовы для исследователей, поскольку нужно найти способ разделения доходов, сгенерированных засчет человеческого капитала и реальных активов.

Однако включение человеческого капитала в структуру финансового потенциала домашних хозяйств подразумевает обязательный расчет его балансовой стоимости. Также в этом случае остро встает вопрос о необходимости учета «нерыночных» видов деятельности. Это связано с тем, что накопление человеческого капитала приводит к повышению производительности труда не только в рыночных (повышение заработной платы, увеличение доходов от предпринимательской деятельности), но и в «нерыночных» видах деятельности. В результате совокупный доход, сформированный за счет имущества, имеющегося у домашних хозяйств, должен содержать величину вмененных нерыночных доходов. Здесь стоит также отметить, что доходы от «нерыночных» видов деятельности аналогичны заработной плате работнику, создаются исключительно за счет человеческого капитала.

В конечном итоге вопрос все же остается дискуссионным. Человеческий капитал может быть как частью финансового потенциала домашних хозяйств, так и исключающим фактором в рассмотрении данного явления. При любых обстоятельствах проблема оценки человеческого капитала остается крайне актуальной.

Проведенные исследования показали, что в настоящее время существует множество методов оценки человеческого капитала, которые обусловлены спецификой рассматриваемого явления. Человеческий капитал одновременно имеет сходные основания как с материальным, так и с нематериальным капиталом, что затрудняет его оценку и определение места в рамках фринансов домашних хозяйств. Несмотря на существующее многообразие, наибольший интерес представляет метод, базирующийся на определении издержек производства, а также метод, отражающий способность человеческого капитала приносить доходы своему владельцу и формировать финансовый результат.

Таким образом, при условии, что место человеческого капитала в структуре финансового потенциаладомашних хозяйств ещене определено, его роль однозначно весома. В результате этого необходимость оценки человеческого капитала остается неизменной. Однако вне зависимости от того, включается он в состав фринансового потенциала или нет, его оценка в рамках рассматриваемого явления обязательна.

\section{СПИСОК ИСПОЛЬЗОВАННОЙ ЛИТЕРАТУРЫ}

1. Самаруха В. И. Финансирование формирования человеческого капитала в муниципальных образовательных системах / В. И. Самаруха, Ю. А. Скоробогатова. - Иркутск : Изд-во БГУЭП, 2009. - 433 с.

2. Курганский С. А. Институциональные аспекты теории человеческого капитала / С. А. Курганский, Н. Н. Даниленко, И. С. Долгополова. - Иркутск : Изд-во БГУЭП, 2005. - 122 с.

3. Schultz T. W. Investment in human capital / T. W. Schultz / / American Economic Review. - 1961. — № 1 (51). - P. 1-17.

4. Becker G. S. Human Capital: A Theoretical and Empirical Analysis, With Special Reference to Education / G. S. Becker. $-2^{\text {nd }}$ ed. - New York : NBER, 1975. - 264 p.

5. Буланов В. Человеческий капитал как фрорма проявления человеческого потенциала / В. Буланов, Е. Катайцева / / Общество и экономика. - 2011. - № 1. - С. 13-22.

6. Жеребин В. М. Экономика домашних хозяйств / В. М. Жеребин, А. Н. Романов. - М. : Финансы : Юнити, 1998. - 231 с.

7. Радаев В. В. Человек в домашнем хозяйстве / В. В. Радаев // Социологические исследования. 1997. - № 4. - C. 64-72.

8. The relation among human capital, productivity and market value: building up from micro evidence / J. M. Abowd et al. // Measuring Capital in the New Economy / ed. by C. Corrado, J. Haltiwanger, D. Sichel. Chicago : Univ. of Chicago Press, 2005. - Vol. 65. - P. 153-204. 
9. Матюшенко Т. А. Развитие финансового потенциала домохозяйств в России : дис. ... канд. экон. наук : 08.00.10 / Т. А. Матюшенко. - М., 2008. - 183 с.

10. Орлов Л. Ф. Теоретические основы фрормирования финансового потенциала домохозяйств / Л. Ф. Орлов // Вестник Московского государственного областного университета. Сер.: Экономика. — 2010. - № 3. C. $36-41$.

11. Боровикова Е. В. Финансовый потенциал как комплексный показатель эффрективности фринансово-бюджетной политики / Е. В. Боровикова / / Экономический анализ: теория и практика. - 2008. - № 18. - С. $25-28$.

12. Николаевская О. А. Реализация инвестиционно-финансового потенциала предприятия / О. А. Николаевская // Финансы и кредит. - 2013. - № 30 (558). - С. 80-85.

13. Булатова Ю. И. Финансовый потенциал региона: содержание и структуры / Ю. И. Булатова / / Вестник Санкт-Петербургского университета. - 2010. - № 3. - С. 94-97.

14. Мерзликина Г. С. Оценка экономической состоятельности предприятия / Г. С. Мерзликина, Л. С. Шаховская. - Волгоград : Изд-во Волгогр. гос. техн. ун-та, 1998. - 256 с.

15. Campbell J. Y. Household finance / J. Y. Campbell // The Journal of Finance. - 2006. - № 4 (61). P. 1553-1604.

16. Samphanttharak K. Household as Corporate Firm: An Analysis of Household Finance Using Integrated Household Survey and Corporate Financial Accounting / K. Samphanttharak, R. M. Townsend. - Cambridge : Cambridge Univ. Press, 2009. - $199 \mathrm{p}$.

17. Barro R. J. International Data on Educational Attainment Updates and Implications / R. J. Barro, J. Lee. Cambridge : NBER, 2000. - 36 p. - (NBER Working Paper ; № 7911).

18. Ciccone A. Human capital, the structure of production, and growth / A. Ciccone, E. Papanioannou // The Review of Economics and Statistics. - 2009. - № 1 (91). - P. 66-82.

19. Machlup F. The Production and Distribution of Knowledge in the United States / F. Machlup. - Princeton : Princeton Univ. Press, 1962. - $416 \mathrm{p}$.

20. Kendrick J. W. The Formation and Stocks of Total Capital / J. W. Kendrick. - New York : NBER, $1976 .-250$ p.

21. Farr W. The income and property tax / W. Farr / / Journal of the Statistical Society of London. - 1853. № 1 (16). - P. 1-44.

22. Капелюшников Р. И. Сколько стоит человеческий капитал России? / Р. И. Капелюшников. - М. : ГУ ВШЭ, 2012. -76 c.

\section{REFERENCES}

1. Samarukha V. I., Skorobogatova Yu. A. Finansirovanie formirovaniya chelovecheskogo kapitala $v$ munitsipal'nykh obrazovatel'nykh sistemakh [Financing Human Capital Formation in Municipal Education Systems]. Irkutsk, Baikal State University of Economics and Law Publ., 2009. 433 p.

2. Kurganskii S. A., Danilenko N. N., Dolgopolova I. S. Institutsional'nye aspekty teorii chelovecheskogo kapitala [Institutional Aspects of the Human Capital Theory]. Irkutsk, Baikal State University of Economics and Law Publ. , 2005. $122 \mathrm{p}$.

3. Schultz T.W. Investment in Human Capital. American Economic Review, 1961, no. 1 (51), pp. 1-17.

4. Becker G. S. Human Capital: A Theoretical and Empirical Analysis, With Special Reference to Education. $2^{\text {nd }}$ ed. New York, NBER, 1975. 264 p.

5. Bulanov V., Kataitseva E. Human Capital as a Form of Human Potential Demonstration. Obshchestvo $i$ ekonomika = Science and Economy, 2011, no. 1, pp. 13-22. (In Russian).

6. Zherebin V. M., Romanov A. N. Ekonomika domashnikh khozyaistv [Economy of Households]. Moscow, Finansy Publ., Yuniti Publ., 1998. 231 p.

7. Radayev V. V. Man in household. Sotsiologicheskie issledovaniya = Sociological Studies, 1997, no. 4, pp. 64-72. (In Russian).

8. Abowd J. M. et al. The relation among human capital, productivity and market value: building up from micro evidence. In Corrado C., Haltiwanger J., Sichel D. (eds). Measuring Capital in the New Economy. University of Chicago Press, 2005, vol. 65, pp. 153-204.

9. Matyushenko T. A. Razvitie finansovogo potentsiala domokhozyaistv v Rossii. Kand. Diss. [Development of Financial Capacity of Households in Russia. Cand. Diss.]. Moscow, 2008. 183 p.

10. Orlov L. F. Theoretical basis of forming the household finance potential. Vestnik Moskovskogo gosudarstvennogo oblastnogo universiteta. Seriya Ekonomika = Bulletin of Moscow University. Series Economics, 2010, no. 3, pp. 36-41. (In Russian).

11. Borovikova E. V. Financial Capacity as an Integrated Index of Fiscal Policy Efficiency. Ekonomicheskii analiz: teoriya i praktika = Economic Analysis: Theory and Practice, 2008, no. 18, pp. 25-28. (In Russian).

12. Nikolaevskaya O. A. Unlocking Finance and Investment Potential of an Enterprise. Finansy $i$ kredit= Finance and Credit, 2013, no. 30 (558), pp. 80-85. (In Russian).

13. Bulatova Yu. I. Financial Potential of the Region: the Content and Structure. Vestnik Sankt-Peterburgskogo gosudarstvennogo universiteta = Vestnik of Saint-Petersburg University, 2010, no. 3, pp. 94-97. (In Russian).

14. Merzlikina G. S., Shakhovskaya L. S. Otsenka ekonomicheskoi sostoyatel' nosti predpriyatiya [Analyzing Economic Solvency of a Company]. Volgograd State Technical University Publ., 1998. 256 p.

15. Campbell J. Y. Household finance. The Journal of Finance, 2006, no. 4 (61), pp. 1553-1604.

16. Samphanttharak K., Townsend R. M. Household as Corporate Firm: An Analysis of Household Finance Using Integrated Household Survey and Corporate Financial Accounting. Cambridge University Press, 2009. 199 p. 
17. Barro R. J., Lee R. J. Lee International Data on Educational Attainment Updates and Implications. NBER Working Paper no. 7911. Cambridge, NBER, 2000. 36 p.

18. Ciccone A., Papanioannou E. Human capital, the structure of production, and growth. The Review of Economics and Statistics, 2009, no. 1 (91), pp. 66-82.

19. Machlup F. The Production and Distribution of Knowledge in the United States. Princeton University Press, 1962. $416 \mathrm{p}$.

20. Kendrick J. W. The Formation and Stocks of Total Capital. New York, NBER, 1976. 250 p.

21. Farr W. The income and property tax. Journal of the Statistical Society of London, 1853, no. 1 (16), pp. 1-44.

22. Kapelyushnikov R. I. Skol'ko stoit chelovecheskii kapital Rossii? [How Much Does Human Capital of Russia Cost?]. Moscow, State University — Higher School of Economics Publ., 2012. 76 p.

\section{Информация об авторе}

Унтанов Александр Баирович - аспирант, кафедра финансов, Байкальский государственный университет, 664003, г. Иркутск, ул. Ленина, 11, e-mail: stalker.pro@bk.ru.

\section{Для цитирования}

Унтанов А. Б. Человеческий капитал как составляющая фринансового потенциала домашних хозяйств / А. Б. Унтанов // Известия Байкальского государственного университета. - 2017. T. 27, № 4. - C. 532-540. - DOI: $10.17150 / 2500-$ 2759.2017.27(4).532-540.

\section{Author}

Aleksander B. Untanov - postgraduate student, Department of Finance, Baikal State University, 11 Lenin St., 664003, Irkutsk, Russian Federation, e-mail: stalker. pro@bk.ru.

\section{For citation}

Untanov A. B. Human Capital as a Component of Household Financial Capacity. Izvestiya Baykal'skogo gosudarstvennogo universiteta $=$ Bulletin of Baikal State University, 2017, vol. 27, no. 4, pp. 532-540. DOl: 10.17150/2500-2759.2017.27(4).532-540. (In Russian). 